\section{Oxidative stress in the development of diabetes during hyperthyroidism}

Sir,

Elevated fasting plasma glucose levels and impaired glucose tolerance are commonly observed as the most significant consequences of thyrotoxicosis. The prevalence of clinical diabetes mellitus is also increased in thyrotoxicosis. ${ }^{1}$ The diabetogenic effect of increased levels of thyroid hormones has variously been attributed to an increased rate of glucose absorption from the gastrointestinal tract, a decreased in the ability of the liver to store glucose as glycogen, increased liver glyconeogenesis, impaired release of pancreatic insulin, and to increased peripheral insulin resistance, as well as to a decreased plasma insulin half-life..$^{2-4}$ Some reports have linked both hyperthyroidism and diabetes mellitus with underlying autoimmune mechanisms rendering cells more susceptible to damage. ${ }^{5}$ The development of diabetes mellitus during hyperthyroidism leads to an aggravation of both diseases, potentiates the development of complications such as ketoacidosis, and may result in increased daily insulin requirements. ${ }^{1}$ We report a patient who developed diabetes mellitus during hyperthyroidism, and suggest that increased oxidative stress during hyperthyroidism may be one of the pathogenetic abnormalities responsible for the development of diabetes.

Hyperthyroidism (toxic adenoma) was first diagnosed in a 35-year old man at our hospital. The diagnosis was based on clinica evaluation, ultrasound scanning, and the following laboratory values: serum thyroxine $187.5 \mathrm{nmol} / \mathrm{l}$ (reference range $55-165 \mathrm{nmol} /$ 1), tri-iodothyronine $3.2 \mathrm{nmol} / 1$ (1.2-2.5), thyroid-stimulating hormone $0.12 \mathrm{mU} / 1$ $(0.17-4.5 \mathrm{mU} / \mathrm{l})$. He was prescribed propylthiouracil at a daily dose of $200 \mathrm{mg}$. Six months later he developed diabetes mellitus. On admission after a further six months, he had poorly controlled diabetes mellitus with a fasting glucose level of $10.9 \mathrm{mmol} / \mathrm{l}$ while taking large doses of insulin $(64 \mathrm{U} / 24 \mathrm{~h}$ in two daily doses). He also had an increased plasma fructosamine level of $0.78 \mathrm{U} / \mathrm{g}$ protein $(0.35$ $0.45 \mathrm{U} / \mathrm{g}$ ), while levels of fasting plasma triglycerides level $(2.76 \mathrm{mmol} / 1)$, cholesterol $(6.7 \mathrm{mmol} / \mathrm{l})$ and $\mathrm{LDL}$ cholesterol $(4.7$ $\mathrm{mmol} / 1$ ) were slightly increased. The level of circulating immune complexes was almost double reference values $(25.4 \mathrm{U} / 1$ vs $6-15$ $\mathrm{U} / \mathrm{l}$ ), while plasma lipid peroxidation products were increased almost four-fold (38.72 $\mu \mathrm{mol} / 1$ vs $6-12 \mu \mathrm{mol} / \mathrm{l})$. The total plasma anti-oxidative capacity was decreased $(64.6 \%$ vs $76-88 \%$ of control range), as was the level of reduced blood glutathione-GSH (0.70 $\mu \mathrm{mol} / \mathrm{ml}$ vs $1.0-1.35 \mathrm{~mol} / \mathrm{ml}$ ).

It was particularly interesting that the hyperthyroidism was accompanied by a significant elevation in the plasma concentration of lipid peroxidation products. It has recently been reported that the levels of free radicals are increased in thyrotoxicosis, as a result of excessive mitochondrial oxygen consumption as well as an increase in the activity of xanthine oxidase. ${ }^{6}$ Free oxygen radicals produced under conditions of increased oxidative stress are capable of decreasing insulin sensitivity and peripheral insulin effectivity, as they are capable of interacting with the insulin-messenger system of NO-guanylate cyclase-cGMP. ${ }^{7}$ Glucose tolerance is dependent on the interaction of tissue sensitivity to insulin and the magnitude of pancreatic insulin secretion. Enhanced production of free oxygen radicals may also cause damage to $\beta$-cells, leading to decreased secretory potential of islet cells, which have very low free-radical scavenging enzyme activity. ${ }^{8} 9$

These observations suggest that increased oxidative stress during hyperthyroidism is capable of promoting the onset of diabetes mellitus, favouring peripheral insulin resistance and exhaustion of $\beta$-cells. This finding could be of pathophysiological importance, not only in explaining some of the basic mechanisms behind the development of impaired glucose tolerance and diabetes during hyperthyroidism, but also in providing a rationale for the use of anti-oxidative drugs at the onset of hyperthyroidism, to prevent or decelerate the development of impaired glucose tolerance and diabetes.

R KOCIC $S$ RADENKOVIC D MIKIC Endocrinology Clinic G KOCIC

T CVETKOVIC D PAVLOVIC

Institute of Biochemistry, Faculty of Medicine University of Nǐ̌, Nǐ̌, Yugoslavia

Correspondence to Dr Radivoj Kocić, ul Nikole Pašića 65/8, 18000 Nišs, Yugoslavia

Accepted 16 December 1997

1 Cooppan R, Kozak GP. Hyperthyroidism and diabetes mellitus. Arch Intern Med 1980;140:370-3.

2 Wajachenberg BL, Cesar FP, Leme CE, Souza Wajachenberg BL, Cesar FP, Leme CE, Souza
IT, Pieroni PR, Mattar E. Carbohydrate metabolism in thyrotoxicosis: studies on insulin tabolism in thyrotoxicosis: studies on insulin secretion before and after remission from the
hyperthyroid state. Horm Metab Res 1978;10: 294-9.

3 Lenzen S. Dose-response studies on the inhibitory effect of thyroid hormones on insulin secretion in the rat. Metabolism 1978;27:81-8.

4 Marecek RL, Feldman JM. Effect of hyperthyroidism on insulin and glucose dinamics in rabbits. Endocrinology 1973;92:1604-11.

5 Volpe R. The role of autoimmunity in hypoendocrine and hyperendocrine function. Ann docrine and hyperendocring

6 Mano T, Shinohara R, Iwase K, et al. Changes in free radical scavengers and lipid peroxide in thyfree radical scavengers and lipid peroxide in thyroid glands of various thy
Metab Res 1997;29:351-4.

7 Wittmann I, Nagy J. Are insulin resistance and atherosclerosis the consequences of oxidative stress? Diabetologia 1996;39:1003-4.

8 Baynes JW Role of oxidative stress in the development of complications in diabetes mellitus. Diabetes 1991;40:405-12.

9 Rossini AA, Mordes JP, Handler ES. Speculation on etiology of diabetes mellitus. Diabetes 1988;37:257-61.

\section{Methotrexate pneumonitis precipitated by NSAIDs - can fish oil help?}

Sir,

We read with interest the article of Clearkin et al describing a case of methotrexate pneumonitis presumably precipitated by concomitant use of diclofenac. ${ }^{1}$ Low-dose methotrexate has become a second-line treatment for patients with rheumatoid arthritis. Nonsteroidal anti-inflammatory drugs (NSAIDs) are frequently coadministered, notwithstanding the fact that such treatment in some cases leads to fatal aggravation of methotrexate toxicity. The mechanism of this is uncertain and may include either displacement of methotrexate from protein-binding sites, or an effect of NSAIDs on the kidney resulting in reduced methotrexate excretion, or both. Conflicting results have been reported with regard to safety of use of ketoprofen and naproxen with methotrexate, ${ }^{23}$ while it has been reported that flurbiprofen or piroxicam in clinically relevant doses do not affect methotrexate disposition in patients receiving low-dose methotrexate

Fish oil supplements have been found to reduce the need for NSAIDs in rheumatoid arthritis. Fish oils are rich sources of polyunsaturated fatty acids of the omega- 3 series. Diets rich in omega-3 fatty acids appear to reduce inflammatory and immune response. Fish oils may be used in doses of 1-2 $\mathrm{g}$ daily without adverse effects. ${ }^{4}$ Encouraging results have also been reported on the beneficial effect of fish oils in diseases such as IgA nephropathy. We speculate that in systemic lupus erythematosus (which is also an extra-articular manifestation of rheumatoid arthritis), fish oils may be beneficial. Clinical studies investigating the effects of fish oils in the prevention and treatment of cardiovascular diseases are beginning to emerge ${ }^{4}$; it is likely that they can minimise the cardiovascular manifestation of rheumatoid arthritis.

We therefore suggest that, in patients with rheumatoid arthritis on low dose methotrexate who require NSAIDs, flurbiprofen or piroxicam may be preferred; further, the addition of fish oil supplements to this regimen may effectively reduce the dose of NSAIDs required and thereby minimise the adverse effects of methotrexate, including pneumonitis. This regimen may also have a beneficial effect on many of the extraarticular manifestations of rheumatoid arthritis. Hence, we feel that a modified therapeutic regimen of low-dose methotrexate and low-dose flurbiprofen/piroxicam with fish oil supplementation, deserves a trial in rheumatoid arthritis.

Fish oil has constraints like higher cost and contains cholesterol. Therefore, alternate vegetable sources of omega- 3 fatty acids, such as walnuts, wheat germ soyabean lecithin tofu, common beans, butternuts and seaweed, all of which are cost-effective and without cholesterol, ${ }^{5}$ could also be included in such a trial.

M THULASIMANI

Department of Clinical Pharmacology, Mahatma Gandhi Dental College and Hospital, Pondicherry 605001, India

S RAMASWAMY

Department of Clinical Pharmacology, Fawaharlal Institute of Postgraduate Medical Education and Research Pondicherry-605006, India

Accepted 19 November 1997

1 Clearkin R. Corris PA, Thomas SHL. Methotrexate pneumonitis in a patient with rheumatrexate pneumonitis in a patient with rheuma
toid arthritis. Postgrad Med f $_{1997 ; 73: 603-4 .}$ 
2 Reynolds JEF. Methotrexate. In: Reynolds JEF ed. Martindale - The extra pharmacopoeia, London: Royal Pharmace

3 Tracy TS, Worster T. Bradley JD, Greena PK, Brater DC. Methotrexate disposition following concomitant administration of ketoprofen piroxicam and flurbiprofen in patients with rheumatoid arthritis. Br f Clin Pharmacol 1994, 37:453-6.

4 Mason P. Fish oils. In: Mason P, ed. Handbook of dietary supplements, Oxford: Blackwell Science Ltd, 1995; pp 73-8.

5 Harvey SC, Withrow CD. Cardiovascular drugs. In: Gennaro AR, ed. Remington's Phardrugs. In: Gennaro AR, ed. Remington's Pharing Company, 1990; pp 858-9.

\section{Thyrotoxicosis and antithyroid drugs}

\section{Sir,}

In their recent self-assessment case on thyrotoxicosis and antithyroid drugs, Monakier and Shilo' ${ }^{1}$ stated in the learning box that once agranulocytosis is diagnosed, antithyroid drugs should be stopped and treatment with granulocyte colony-stimulating factors (GCSFs) initiated, in addition to isolation and antibiotic administration. They did not mention the importance of the duration of the neutropenia in deciding to starting therapy with G-CSF. In 1996 a panel convened by the American Society of Clinical Oncology concluded that G-CSF or GM-CSF is unnecessary in patients with neutropenia of short duration (less than a week), but that it may benefit patients with prolonged neutropenia. ${ }^{2}$ Thus, it was probably unnecessary to treat their patient with G-CSF.

MOHAMMED R MAJEED Department of Molecular Medicine, University of Auckland, Private Bag 92019, Auckland, New Zealand

Accepted 19 November 1997

1 Monakier D, Shilo S. Thyrotoxicosis and antithyroid drugs. Postgrad Med $\mathcal{f}$ 1997;73:335-

2 American Society of Clinical Oncology. Update of recommendations for the use of hematopoiof recommendations for the use of hematopoi-
etic colony-stimulating factors: evidence based etic colony-stimulating factors: evidence based
clinical practice guidelines. $\mathcal{F}$ Clin Oncol 1996; clinical practice

This letter was forwarded to the authors who responded as follows:

Sir,

The American Society of Clinical Oncology paper you mention deals with the use of haematopoietic CSF following chemotherapy and does not deal with other drug-induced neutropenia. It states: “... Existing clinical data suggest that starting G-CSF or GMCSF between 24 and 72 hours subsequent to chemotherapy may provide optimal neutrophil recovery". (p 1959, para 10). The recommendation is to start CSF even before the appearance of agranulocytosis. Our recommendation, in a case of agranulocytosisis induced by antithyroid medications, is to start CSF when agranulocyctosis appears, in order to try and avoid fever and infections and to reduce infection complications.

S SHILO

Endocrine Service, Shaare Zedek Medical Centre, ferusalem, PO Box 3235, ferusalem, Israel 91035

\section{Sarcoidosis-lymphoma syndrome in a woman with acromegaly}

Sir

We read the article by Romero et al on sarcoidosis-lymphoma syndrome ${ }^{1}$ with great interest. We would like to report a case of a woman with acromegaly in whom nonHodgkin's lymphoma was diagnosed 6 years after sarcoidosis.

In 1979, a 38-year-old woman was admitted with complaints of irregular fever and cervical lymphadenopathy. She had a history of active acromegaly which had been treated by local pituitary ${ }^{60} \mathrm{Co}$ irradiation (3340 cGy in 20 fractions) two years earlier. At presentation she was in a good clinical condition. Physical examination revealed bilateral, movable cervical and supraclavicular enlarged lymph nodes without hepatosplenomegaly. Chest X-ray was normal. Lymphography showed retroperitoneal and bilateral inguinal lymphadenopathy. Full blood counts were normal; the erythrocyte sedimentation rate was $35 \mathrm{~mm} / \mathrm{h}$. After histological examination of two cervical lymph nodes, a diagnosis of sarcoidosis was established. She was put on $45 \mathrm{mg}$ of prednisolone daily. After symptoms subsided, steroid therapy was continued for one year.

She remained asymptomatic for a follow-up period of 5 years. In 1986 she was again admitted to hospital with fever, weight loss, goitre and cervical lymphadenopathy. Her symptoms did not subside on 6 months ambulatory treatment with steroids. Other clinical examination findings were hilar enlargement, revealed on chest X-ray, and lymphatic infiltration of bone marrow (up to $20 \%$ ). Histological examination of the cervical node demonstrated centroblastic lymphoma. The patient received six courses of CVP chemotherapy (cyclophosphamide, vincristin and prednisolone). A reduction of symptoms, including a reduction of the enlarged lymph nodes and goitre, were noted. The patient remains asymptomatic.

Brincker, in his description of so-called sarcoidosis-lymphoma syndrome ${ }^{2}$ pointed to three typical features: sarcoidosis preceeds lymphoma by several years, the patients are on average 10 years older than other patients with sarcoidosis, and an association with Hodgkin's lymphoma is more frequent. Our patient met two of these three criteria. She was in her forties when she developed sarcoidosis. She had received steroid treatment and developed lymphoma 6 years after the diagnosis of sarcoidosis.

The immunologic abnormalities in our patient could have been initiated by radiotherapy. This might have provoked the development of sarcoidosis. Consequently an increased mitotic activity and dysregulation of lymphocytes observed in sarcoidosis, ${ }^{34}$ as well as steroid therapy, contributed to the development of lymphoma. We believe that our case supports the theory of non-random association between sarcoidosis and lymphoma and the existence of sarcoidosis-lymphoma syndrome.

M SIEKIERSKA-HELLMANN K SWORCZAK

Division of Endocrinology

$3^{\text {rd }}$ Department of Internal Medicine,

Medical University of Gdañsk, Poland

Accepted 21 January 1998

1 Romero J, Ramon y Cajal S, Vargas JA, et al. Association of sarcoidosis, low-grade B-lymphoma and epidermoid carcinoma. Postgrad Med f 1997;73:580-4.

2 Brincker H. The sarcoidosis-lymphoma synBrincker $H$. The sarcoidosis-lymph
drome. Br $f$ Cancer 1986;54:467-73.

3 Danielle RP, Dauber JH, Rossmann MD. Danielle RP, Dauber JH, Rossmann $\mathrm{MD}$.
Immunologic abnormalities in sarcoidosis. Ann Intern Med 1980;92:406-11.

4 Linnenberg HS, Medici TC, Rhynet K. Das 'Sarkoidosis-Lymphoma-Syndrom'-Eine Lymphozyten Fehlregulation? Pneumonologie 1992;46:229-35.

\section{Understanding scientific papers}

Sir

We would like to offer an addendum to the articles published in recent years in various journals ${ }^{12}$ on how to read medical literature. This addendum, a translation of some of the phrases commonly used in scientific and clinical articles, has been gleaned from various sources and we have made some modifications of our own. We hope that readers will find it both instructive and amusing.

- It has long been known that... = We haven't bothered to look up the relevant literature or the original reference.

- While it has not been possible to provide definite answers to these questions... = The experiment did not work out, but we figured we could at least get a publication out of it.

- Typical results are shown... = Only the positive results are shown.

- It is suggested/believed... = We think.

- It is generally suggested/believed... = A couple of other guys think so too.

- It is clear that much additional work will be required before a complete analysis of the results... = We don't understand what happened.

- Unfortunately, a quantitative theory to account for the results has not yet been formulated... $=$ No one else understands it either.

- Correct within an order of magnitude = Wrong.

- It is clear... = It is not clear.

- It is obvious... = We think that is the way it should be, but we cannot explain why.

RAZ GROSS

The Chaim Sheba Medical Center, Tel Hashomer, Israel ALAN DEROWE

Meir Hospital, Sapir Medical Center, Kfar Sava, Israel

Correspondence to Raz Gross, MD, 36 King David Blvd, Tel Aviv 64237, Israel

Accepted 19 November 1997

1 Greenhalgh T. How to read a paper: Getting your bearings (deciding what the paper is about). BMF 1997;315:243-6.

2 Guyatt GH, Rennie D. User's guides to the medical literature. $\mathcal{F A M A}$ 1993;270:2096-7. 